\title{
ガスクロマトグラフィーによる胃腸薬中の ジメチルポリシロキサンの定量
}

\author{
金子彰治®，対馬勇禧，吉田 豊，栢野正則* \\ (1985 年 9 月 17 日受理)
}

\begin{abstract}
胃腸薬中のジメチルポリシロキサン (DMPS) の定量法として，DMPS とケイ酸エチルをフルカリ の存在下で反応させ，生成したジメチルジェトキシシランをガスクロマトグラフィーで測定する方法を 検討した。 カラム充てえ剂には吸着系の Diasolid ZF を用い，水素フレームイオン化検出器によって 検出した。一般に，製剂中のシリコン化合物は賦形剂に強く吸着されており抽出が困難であるが，本定 量法によると DMPS は勃率良くジメチルジェトキシシランに変換されるため, 高い回収率が得られ, 操作が簡便でしかも精度良く製郕中の DMPS を定量することができた.
\end{abstract}

\section{1 緒 言}

ジメチルポリシロキサン (DMPS) は, 消泡作用, 胃 内有泡性粘液除去作用を有し，医療用医薬品の消化管内 ガス排除剂として市販されている. 胃腸薬製造承認基準 によると本成分は, 制酸剂, 健胃剂, 消化剂及び整腸剂 に佐薬として配合することができる1). 特に制酸剤配合 の胃腸薬においては, DMPS の配合による消泡効果が 期待される.

DMPS の定量法としては, 重量法2), 比色定量法3), 原子吸光光度法 ${ }^{4)}$, 赤外吸収法5) などがあるが，製剤中 の DMPS の定量に応用するには, 抽出率が低いことや 操作が煩雑であることなどの問題がある. そこで著者ら はDMPS を配合した製剤について操作が簡便でしかも 精度の良い定量法を確立するため, 種々の方法について 検討を行った.

その結果, Vornokov6)7) らの報告にあるアルカリの存 在下で DMPS とケイ酸エチルからエトキシシランが生 成する反応を利用し，生成したジメチルジェトキシシラ ン (DMES) をガスクロマトグラフィー (GG) によっ て测定することにより DMPS を定量する方法を確立し た.

\section{2 装置と試薬}

\section{1 装 置}

ガスクロマトグラフ：日立製 263-80 型に同社製 263-

*ェーザイ(株)技術研究センター：367 埼玉県本庄 市南 2-3-14
80 型 GG コントローラーを接続して用いた.

カラム：日本クロマト工業製 Diasolid ZF (80〜100 メッシュ）を内径 $3 \mathrm{~mm}$ ，長さ $2 \mathrm{~m}$ のガラスカラムに 充てんして用いた .

キャリヤーガスには窒素を用い, 流量は毎分 $30 \mathrm{ml}$ とした. 又, カラム温度を $50^{\circ} \mathrm{C}$, 試料注入口温度を $100^{\circ} \mathrm{G}$ とし, 検出器には水素フレームイオン化検出器 (FID)を用いた.

\section{2 試 薬}

DMPS : 信越化学製の DMPS（重合度約 150）を用い た.

標準原液: DMPS を $1.25 \mathrm{mg} / \mathrm{ml}$ の濃度となるよう にケイ酸ェチルに溶解して調製した.

ヘキサメチルジシロキサン: 信越化学製を用いた.

水酸化カリウム, ケイ酸エチルは市販の特級品を用い た。

\section{3 実験}

\section{1 試料の調製}

制酸剤（水酸化アルミニウムー炭酸マグネシウムー炭酸 カルシウム共沈物 : $350 \mathrm{mg}$, 合成ヒドロタルサイト： $300 \mathrm{mg}$, ロートエキス散: $100 \mathrm{mg}$, 炭酸水素ナトリウ ム: $190 \mathrm{mg}$ ), 粘膜修復剤（銅クロロフィリンナトリウ ム : $30 \mathrm{mg}$ ) 及び DMPS $20 \mathrm{mg}$ を顆粒剤は $1.3 \mathrm{~g}$ 中に， 錠剂は $1.2 \mathrm{~g}$ 中に各々配合しその他賦形剂を処方して 調製し試料とした.

\section{2 定量操作}

DMPS 約 $10 \mathrm{mg}$ に相当する量の試料の粉末を精ひょ 
らし,ヶイ酸エチル $8 \mathrm{ml}$ 及び水酸化カリウム $0.4 \mathrm{~g}$ を 加光冷却管を付けて, $160 \sim 180^{\circ} \mathrm{C}$ で 30 分間還流操作 を行う. 冷後, 約 $190^{\circ} \mathrm{G}$ の油浴を用いて蒸留を行い受 け器を冷却しながら留液（約 $7 \mathrm{ml}$ ) を集め, ケイ酸エチ ルを加えて正確に $10 \mathrm{ml}$ とし, 試料溶液とする. 又, 標準原液を正確に $8 \mathrm{ml}$ (DMPS として $10 \mathrm{mg}$ ) 採り水 酸化カリウム $0.4 \mathrm{~g}$ を加克, 以下試料と同様に操作した ものを標準溶液とする。

試料溶液と標準溶液についてその $10 \mu \mathrm{l}$ をマクロシ リンジによりガスクロマトグラフに注入し，得られたク ロマトグラムの DMES のピーク面積を求め, 絶対検量 線法により DMPS 含有量を計算する.

\section{4 結果と考察}

\section{1 反応生成物の確認}

アルカリの存在下で，DMPS とケイ酸エチルとを反 応させると式(1) のように, トリメチルエトキシシラン (TMES) と DMES が生成する67)。 そこで，これらの 生成物について確認を行った. TMES についてはジメ チルシロキサン基のないれキサメチルジシロキサンをア ルカリの存在下でケイ酸エチルと反応させて別途合成 し，これと同定した. その結果, 本法の条件では Fig. 1 亿示したように TMES (保持時間: 0.8 分), DMES (保持時間 $: 1.8$ 分) 及び溶媒の順に GC カラムから溶 出することが確認され, 本法では生成量の多い DMES のピークを定量に用いることとした．

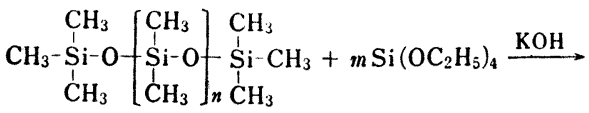

$$
\begin{aligned}
& 2\left(\mathrm{CH}_{3}\right)_{3} \mathrm{SiOC}_{2} \mathrm{H}_{5}+n\left(\mathrm{CH}_{3}\right)_{2} \mathrm{Si}\left(\mathrm{OC}_{2} \mathrm{H}_{5}\right)_{2}
\end{aligned}
$$

\section{2 水酸化カリゥム量及び反応時間の検討}

反応温度は約 $170^{\circ} \mathrm{C}$ 没設定し, 水酸化カリウム量及 び反応時間（還流時間）の検討を行った.

4.2.1 水酸化カリゥム量の検討 水酸化カリウムを ケイ酸エチル $8 \mathrm{ml}$ 当たり $0 \sim 1 \mathrm{~g}$ まで添加し, DMPS からの DMES の生成率を比較した. その結果, Fig. 2 から分かるように水酸化カリウム量が $0.3 \mathrm{~g}$ から $0.5 \mathrm{~g}$ の間で DMES の生成は顆粒剤, 錠剂ともに添ぼ定量的 であった. そこで, 本法では水酸化カリウムの添加量を $0.4 \mathrm{~g}$ とした.

4.2.2 反応時間の検討 反応時間を 5 分から 60 分 まで変えて検討した結果を Fig. 3 亿示した. 顆粒郕,

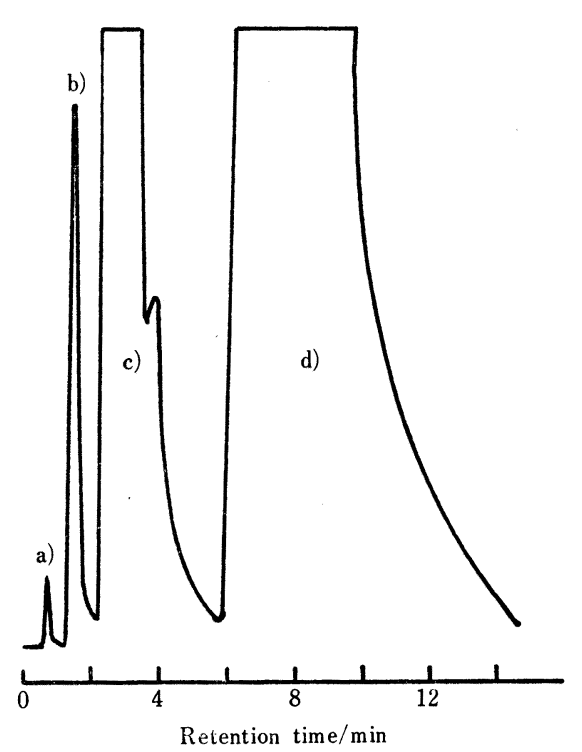

Fig. 1 Gas chromatogram for dimethylpolysiloxane (DMPS) standard solution

Concentration of DMPS solution : $1.0 \mathrm{mg} / \mathrm{ml}$ in ethylsilicate; Peaks : a) trimethylethoxysilane (TMES), $\left.R_{\mathrm{t}} 0.8 \mathrm{~min}, \mathrm{~b}\right)$ dimethyldiethoxysilane (DMES), $\left.R_{\mathrm{t}} 1.8 \mathrm{~min}, \mathrm{c}\right)$, d) solvent; Chromatographic conditions-apparatus : Hitachi model 263-80, column : a glass column $(3 \mathrm{~mm}$ i.d. $\times 2 \mathrm{~m})$ packed with Diasolid ZF (80 100 mesh) (Nihon Kuromato Kogyou Co.); Temperature : column $50^{\circ} \mathrm{C}$, injection $100^{\circ} \mathrm{C}$; Detector : flame ionization detector; Carrier gas : nitrogen (flow rate 30 $\mathrm{ml} / \mathrm{min}$ )

錠剤とも 20 分以降では DMES の生成がほぼ定量的で あることが分かったとこてて，還流時間を 30 分に決定 した。

\section{3 検量線}

$0.4 \sim 1.2 \mathrm{mg} / \mathrm{ml}$ の範囲で DMPS の濃度とクロマト グラム上の DMES のピーク面積の間に直線関係 $(Y=$ $7.26 X+30.3, r=0.998)$ が得られた. 回㷌式の $Y$ 軸切 片がプラス側にあるのは，DMES の次に溶出するヶイ 酸エチルのピークが大きいためと思われる.

\section{4 添加回収実験}

顆粒剂及び錠剤の配合成分から DMPS だけを除いた 試料を各々調製し, 顆粒剤は $1.3 \mathrm{~g}$, 錠郕は $1.2 \mathrm{~g}$ を量 り採った。 これらに DMPSを 8〜24 mg の簌囲（処方 量の $40 \sim 120 \%$ に相当）で溶液及び練り込久による添加 


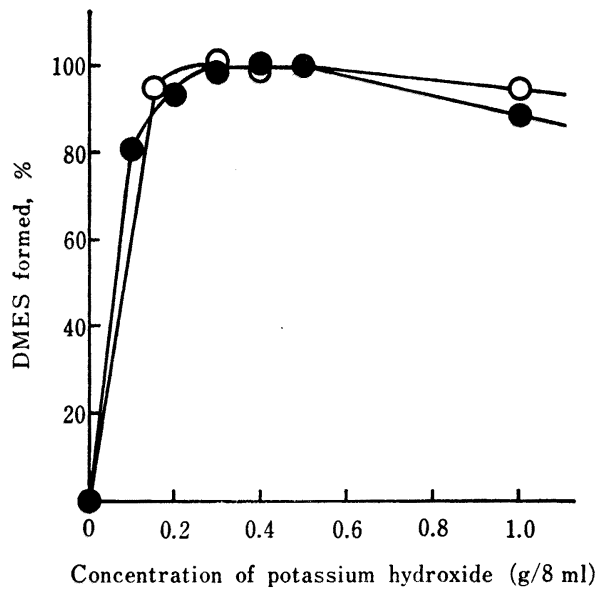

Fig. 2 Effect of potassium hydroxide concentration on the formation of DMES from DMPS

DMES formed by the reaction between DMPS and ethyl silicate is shown as percentage of observed value to theoretical value. $\bigcirc:$ granules, : tablets. Components : the same as those shown in Table 1 and DMPS $20 \mathrm{mg}$. Total weight used : granule $1.3 \mathrm{~g}$, tablet $1.2 \mathrm{~g}$. Method: Take appropriate amount of powdered drug containing about $10 \mathrm{mg}$ of DMPS, add $8 \mathrm{ml}$ of ethyl silicate and $0.4 \mathrm{~g}$ of potassium hydroxide, and reflux for $30 \mathrm{~min}$ at $160 \sim 180^{\circ} \mathrm{C}$.

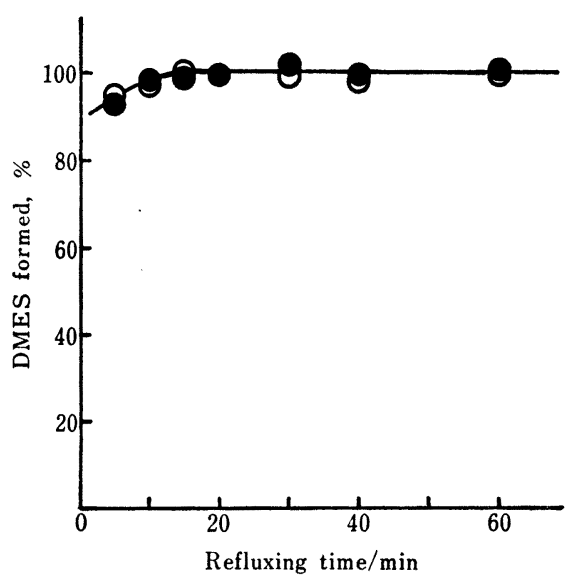

Fig. 3 Effect of refluxing time on the formation of DMES from DMPS

$\mathrm{O}$ : granules,

: tablets. See footnote of Fig. 2.

を行い回収実験を実施した. その結果, Table 1 に示 したようにいずれも 97〜110\% と良好な回収率を得た. 低い添加量に扣いては，ほかよりも回収率が 6〜10\% 程
Table 1 Recovery of DMPS from granules and tablets

\begin{tabular}{|c|c|c|c|c|}
\hline & \multicolumn{2}{|c|}{ Added as solution } & \multicolumn{2}{|c|}{$\begin{array}{l}\text { Added in the } \\
\text { preparation process }\end{array}$} \\
\hline & $\begin{array}{l}\text { DMPS } \\
\text { added/mg }\end{array}$ & $\begin{array}{l}\text { Recov- } \\
\text { ery, \% }\end{array}$ & $\begin{array}{l}\text { DMPS } \\
\text { added/mg }\end{array}$ & $\begin{array}{l}\text { Recov- } \\
\text { ery, \% }\end{array}$ \\
\hline \multirow[t]{6}{*}{ Granule } & 0 & (nd) $t$ & - & - \\
\hline & 8 & 109 & 8 & 110 \\
\hline & 12 & 104 & 12 & 104 \\
\hline & 16 & 102 & 16 & 104 \\
\hline & 20 & 102 & 20 & 102 \\
\hline & 24 & 101 & 24 & 97 \\
\hline \multirow[t]{6}{*}{ Tablet } & 0 & (nd) & - & - \\
\hline & 8 & 106 & 8 & 108 \\
\hline & 12 & 105 & 12 & 104 \\
\hline & 16 & 100 & 16 & 101 \\
\hline & 20 & 102 & 20 & 97 \\
\hline & 24 & 98 & 24 & 98 \\
\hline
\end{tabular}

$\dagger$ Not detected. Components : coprecipitate of aluminium hydroxide, magnesium carbonate and calcium carbonate $350 \mathrm{mg}$; hydrotalcite, synthetic $300 \mathrm{mg}$; scopolia extract $100 \mathrm{mg}$; sodium bicarbonate $190 \mathrm{mg}$; sodium copper chlorophyllin $30 \mathrm{mg}$; and some ingredients. Total weight used: granule $1.3 \mathrm{~g}$, tablet $1.2 \mathrm{~g}$

度高い結果となったが，この原因はヶイ酸エチルのピー クが大さいことに起因するプラスの妨害によるものと考 学らる. しかし，処方量の 80１20\% の範囲（16２4 $\mathrm{mg}$ 添加量) では 97〜104\% の回収率が得られて扒り， 製剤の品質試験のための定量法として満足できるものと 考学る.

なお，顆粒剤及び錠剤の配合成分から DMPS だけを 除いた試料ではクロマトグラム上の TMES 及び DMES の溶出位置にピークは認められなかった.

\section{5 試料の分析及び定量の精度}

試作した顆粒剤と錠郕の試料各 3 ロットを本法により 分析した結果を Table 2 と示した. これより配合量に

Table 2 Analytical results of DMPS in granules and tablets prepared in our laboratory

\begin{tabular}{lcccc}
\hline & $\begin{array}{c}\text { Sample } \\
\text { No. }\end{array}$ & \multicolumn{2}{c}{$\begin{array}{c}\text { DMPS (granule }: \mathrm{mg} / 1.3 \mathrm{~g}, \\
\text { tablet }: \mathrm{mg} / 1.2 \mathrm{~g})\end{array}$} \\
\cline { 3 - 5 } Added & Found (recovery, \%) \\
\hline Granule & 1 & 20.0 & 19.94 & $(99.7)$ \\
& 2 & 20.0 & 19.88 & $(99.4)$ \\
Tablet & 3 & 20.0 & 19.92 & $(99.6)$ \\
& 1 & 20.0 & 19.66 & $(98.3)$ \\
& 2 & 20.0 & 20.19 & $(101.0)$ \\
& 3 & 20.0 & 19.96 & $(99.8)$ \\
\hline
\end{tabular}


対しほぼ 100\% の定量值が得られていることが分かっ た. 又錠剤の試料 1 を使用して行った繰り返し実験 $(n$ $=10$ ) では, 平均值 $19.62 \mathrm{mg} / 1.2 \mathrm{~g}$ (配合量の $98.1 \%$ ), 相対標準偏差 $2.98 \%$ と再現精度も良好であり, 十分実 用可能なことが確認できた.

なお，多量のケイ酸エチルを注入するため FID のミ クロバーナーの周辺が污れ, 検出感度の低下が懸念され

る.そこで, これらの影響を除くため, 試料溶液を 3 回 注入する前後に標準溶液を注入し, それらのクロマトグ ラムから得られた DMES のピーク面積の平均值を基に 試料中の含有量を計算した. 又, 測定終了時には燃焼部 分の清掃を行った. 本実験期間（約 2 か月）中にはカラ ム充てん剂の劣化は認められなかった.

本法は製剤中の賦形剤などに吸着された DMPS に対 しても有効であり，しかも操作が簡便で精度良く製剤中 の DMPS を定量しうる優れた方法と思われる.

\section{交献}

1）日本公定書協会編：“医薬品製造指針”， p. 221 (1984)，(薬業時報社).

2）石館守三監修：“第四版食品添加物公定書解説 書”, B-547 (1979), (廣川書店).

3) W. Fresenius : Fresenius' Z. Anal. Chem., 207, 16 (1965).

4) G. M. Paralusz : Appl. Spectrosc., 22, 520(1968).

5) J. G. B. Smith : Analyst(London), 85, 465(1960).

6) M. G. Voronkov : J. Gen. Chem. USSR, 29, 890 (1959).

7) M. G. Voronkov, Z. I. Shabarova : J. Gen. Chem. USSR, 29, 1501 (1959).
Gas chromatographic determination of dimethylpolysiloxane in gastrointestinal drugs. Syoji Kaneko, Yuki Tsushima, Yutaka Yoshida and Masanori Kayano (Research Center of Technological Development, Eisai Co., Ltd., 2-3-14 Minami, Honjo-shi, Saitama 367)

A simple and accurate gas chromatographic method for the determination of dimethylpolysiloxane(DMPS) in gastrointestinal drugs was established. This method is based on the formation of dimethyldiethoxysilane (DMES) by the reaction between DMPS and ethyl silicate under alkaline condition. The procedure is as follows: Take appropriate amount of powdered drug containing about $10 \mathrm{mg}$ of DMPS, add $8 \mathrm{ml}$ of ethyl silicate and $0.4 \mathrm{~g}$ of potassium hydroxide, and reflux for $30 \mathrm{~min}$ at $160 \sim 180^{\circ} \mathrm{C}$. After cooling, distill the reaction mixture, and collect about $7 \mathrm{ml}$ of distillate. Make the volume of the distillate up to $10 \mathrm{ml}$ with ethyl silicate. Inject $10 \mu \mathrm{l}$ of this solution into gas chromatograph, and calculate the content of DMPS in the drug from calibration curve based on peak area of DMES. Gas chromatographic conditions are as follows: Column; Diasolid ZF (3 mm i.d. $\times 2 \mathrm{~m}$ ), column temp.; $50^{\circ} \mathrm{C}$, injection temp.; $100^{\circ} \mathrm{C}$, detector; flame ionization detector. The calibration curve was linear in the range of $0.4 \sim 1.2 \mathrm{mg} / \mathrm{ml}$ of DMPS. Recoveries of DMPS from drugs tested were quantitative. Ten replicate determination of a drug containing 20.0 $\mathrm{mg} / 1.2 \mathrm{~g}$ of DMPS gave average value of $19.62 \mathrm{mg} / 1.2$ $\mathrm{g}(98.1 \%)$ and relative standard deviation of $2.98 \%$.

(Received September 17, 1985)

\section{Keyword phrases}

gas chromatographic determination of dimethylpolysiloxane in gastrointestinal drugs; formation and detection of dimethydiethoxysilane. 